\title{
Approaches for Understanding the Mechanisms of Long Noncoding RNA Regulation of Gene Expression
}

\author{
Patrick McDonel ${ }^{1}$ and Mitchell Guttman ${ }^{2}$ \\ ${ }^{1}$ Program in Bioinformatics and Integrative Biology, University of Massachusetts Medical School, Worcester, \\ Massachusetts 01655 \\ ${ }^{2}$ Division of Biology and Biological Engineering, California Institute of Technology, Pasadena, California 91125 \\ Correspondence: mguttman@caltech.edu
}

\section{SUMMARY}

Mammalian genomes encode tens of thousands of long noncoding RNAs (IncRNAs) that have been implicated in a diverse array of biological processes and human diseases. In recent years, the development of new tools for studying IncRNAs has enabled important progress in defining the mechanisms by which Xist and other IncRNAs function. This collective work provides a framework for how to define the mechanisms by which IncRNAs act. This includes defining IncRNA function, identifying and characterizing IncRNA-protein interactions, and IncRNA localization in the cell. In this review, we discuss various experimental approaches for deciphering IncRNA mechanisms and discuss issues and limitations in interpreting these results. We explore what these data can reveal about IncRNA function and mechanism as well as emerging insights into IncRNA biology that have been derived from these studies.

\section{Outline}

1 Introduction

2 Methods for defining IncRNA function

3 Defining IncRNA-protein interactions and their functional contributions

4 Methods for determining where IncRNAs localize
5 Future directions: IncRNAs and phase separation in the nucleus

References 


\section{INTRODUCTION}

Over the last decade, tens of thousands of long noncoding RNAs (lncRNAs) have been discovered in mammalian genomes, with their numbers likely to eclipse the number of proteins (Guttman et al. 2009; Derrien et al. 2012). IncRNAs generally have similar properties to messenger RNAs in that they are often spliced, $5^{\prime}$-capped, and polyadenylated (Cabili et al. 2011; Derrien et al. 2012), yet are not translated into a protein product and instead function as an RNA molecule (Guttman et al. 2013). lncRNAs range in size from hundreds to tens of thousands of nucleotides in length, are expressed across a wide range of levels (Cabili et al. 2011; Derrien et al. 2012), and can localize to target sites within the nucleus or cytoplasm of the cell (Khalil et al. 2009; Cabili et al. 2015; Werner and Ruthenburg 2015). lncRNAs have begun to take a center stage in many aspects of biology, having been shown to play essential roles in diverse biological processes from development to immune responses (Rinn and Chang 2012; Sauvageau et al. 2013), and hundreds of lncRNAs are amplified, deleted, or otherwise disrupted in various human cancers and diseases (Wapinski and Chang 2011). Yet, despite the increasing prominence of lncRNAs in biology and disease, we still know very little about the mechanisms by which most lncRNAs act (Rinn and Chang 2012; Engreitz et al. 2016b), largely because they remain difficult to study.

The best-studied IncRNA is Xist, which orchestrates $\mathrm{X}$-chromosome inactivation (XCI), an essential developmental process that ensures proper expression balance of genes on the X chromosome in female mammals ( $\mathrm{da}$ Rocha and Heard 2017). Xist localizes across the entire X chromosome (Clemson et al. 1996; Engreitz et al. 2013), recruits repressive chromatin proteins to these sites (Plath et al. 2003; McHugh et al. 2015), triggers chromosome-wide transcriptional silencing (Penny et al. 1996; Wutz et al. 2002; McHugh et al. 2015), and mediates a cascade of chromosome structure changes and chromatin modifications to maintain this silenced state (da Rocha and Heard 2017).

Deciphering the mechanism by which Xist orchestrates $\mathrm{XCI}$ by modulating chromatin structure and silencing gene expression required the work of many laboratories and nearly 25 years of effort (da Rocha and Heard 2017). In addition to chromatin regulation, we now know that lncRNAs can play other roles in posttranscriptional gene regulation. For example, Malat1 localizes with nascent precursor messenger RNA (pre-mRNA) (Engreitz et al. 2014; West et al. 2014) around nuclear speckles (Spector and Lamond 2011), interacts with various splicing and mRNA processing proteins, and may act to control alternative splicing (Tripathi et al. 2010). Neatl can act to nucleate the establishment of a nuclear territory called the paraspeckle (Clemson et al. 2009), which contains various mRNA species of unknown identity (Fox et al. 2018). In the cytoplasm, NORAD can interact with mRNA translation proteins (e.g., Pumilio) and may act to titrate these proteins away from specific mRNA targets to regulate mRNA translation (Lee et al. 2016). These examples highlight the diverse roles that $\operatorname{lncRNAs}$ can play by interacting with different molecules in different cellular locations (Kopp and Mendell 2018).

In recent years, the development of new tools for studying $\operatorname{lncRNAs}$ has enabled important progress and has begun to uncover key aspects of the mechanisms by which Xist and other lncRNAs work (Engreitz et al. 2016b; Kopp and Mendell 2018). This collective work provides a framework for how to define lncRNA function and mechanism. Specifically, deciphering these mechanisms required (1) determining that the lncRNA acts as a functional RNA molecule, (2) comprehensively defining the proteins that interact with the lncRNA, (3) defining where the lncRNA binds (to genomic DNA or RNA) and in what precise location within the cell, and (4) determining how these RNA-protein components are integrated to control cellular function.

In this review, we will explore how information about lncRNA protein binding, genomic and cellular localization, and function can be integrated to understand the mechanisms of lncRNAs in gene regulation, and we will discuss the methods used for exploring these questions.

\section{METHODS FOR DEFINING IncRNA FUNCTION}

Understanding how any lncRNA controls cellular function requires direct perturbation followed by observations of the functional consequences in vivo (e.g., cells, tissues, or animal models). Yet, this remains challenging in practicemore so than disrupting protein-coding genes. Whereas protein-coding genes can be disrupted through small frameshift mutations in the coding sequence, we do not know a priori which parts of a lncRNA sequence are necessary for its function and therefore whether short insertions/ deletions should disrupt its function. This necessitates larger deletions, such as deletion of the entire genomic locus, to confidently disrupt the IncRNA function. Indeed, this was precisely how Xist was initially characterized. Shortly after Xist was identified as a transcript expressed from the inactive $\mathrm{X}$ chromosome (Xi) but not the active X (Brockdorff et al. 1991; Brown et al. 1991), it was shown that cells containing a deletion of the Xist locus failed to initiate XCI (Penny et al. 1996).

However, large deletions frequently have unintended consequences, such as by removing DNA regulatory ele- 
ments contained within the lncRNA locus that can affect nearby genes (Groff et al. 2016; Engreitz et al. 2016a). These considerations must be taken into account when designing deletion experiments and interpreting their results. In fact, a recent study genetically deleted 12 lncRNA loci and found that five regulate the expression of a neighboring gene through mechanisms that do not involve the lncRNA transcript itself. Instead, several of these IncRNA promoters acted at the DNA level as cis-regulatory elements (enhancers) that controlled another neighboring gene, whereas others controlled expression of neighboring genes in a manner that was dependent on the active transcription-but not the sequence-of the IncRNA gene (Engreitz et al. 2016a).

Accordingly, orthogonal approaches are required to eliminate lncRNA expression to show whether a genetic locus functions through an encoded lncRNA (Engreitz et al. 2016a). In the case of Xist, additional observations were required to show that it acts as a functional RNA molecule. Specifically, (1) the Xist RNA was shown to form a unique nuclear compartment that "coats" the Xi (Clemson et al. 1996); (2) forced expression of Xist on $\mathrm{X}$ chromosomes or autosomes, in females or males, was shown to be sufficient to trigger gene silencing in cis (Wutz et al. 2002); and (3) deletion of a single region of the Xist RNA, called the A-repeat, ablates its silencing role (Wutz et al. 2002) but not its localization to Xi. Together, these sets of experiments established that the Xist RNA itself is required for initiating the process of XCI.

In this section, we will describe the various perturbation strategies for studying lncRNAs (Fig. 1) and discuss the considerations associated with interpreting each of these approaches to establish the functional role of a lncRNA in vivo.

\subsection{Inhibition of Transcriptional Initiation}

To account for the issues that arise from deleting a lncRNA locus, which can often entail deletion of thousands of nucleotides, one approach is to make a more precise deletion that simply removes the promoter region of a lncRNA transcript. This entails ablating transcription of the locus using CRISPR to delete the promoter. A similar approach is to use CRISPR interference (CRISPRi), in which a repressive protein is recruited to the promoter region of a lncRNA to block transcriptional initiation of the locus (Liu et al. 2016). Although these approaches can define whether a lncRNA-encoding locus has an effect on gene expression, it cannot distinguish between an RNA-independent (e.g., cis-regulatory elements or RNA transcription) and RNAdirected mechanism because CRISPRi is known to also inhibit the activity of cis-regulatory elements and preclude transcription (Fulco et al. 2016).

\subsection{Premature Transcriptional Termination}

Another approach is to retain the promoter and transcriptional initiation of the locus while eliminating the mature RNA product. One way to achieve this is through the insertion of a polyadenylation site downstream from the transcription start site, which will lead to premature termination of transcription, reduce transcription in the locus, and eliminate the mature RNA while leaving the promoter sequence intact. If a phenotype is observed in this way, one can conclude that the phenotype is not dependent on a cis-regulatory element but instead requires transcription activity at the locus. Yet, this approach does not fully discriminate between a sequence-dependent role for the lncRNA and the active process of transcription across the lncRNA locus.

\subsection{Precise Sequence-Specific Mutagenesis and Functional Rescue}

One approach to directly determine whether a lncRNA has a sequence-specific function is to delete precise sequences within the lncRNA. For example, deleting or mutating a specific protein binding site contained within a lncRNA should distinguish between sequence-independent effects of lncRNA transcription and sequence-specific effects of the lncRNA itself. This approach also has the benefit of allowing specific functions to be assigned to the mutated domains. Because this approach is often associated with identification of the proteins that interact with a specific region of a lncRNA, such perturbations can be directly complemented by functional rescue experiments that establish a direct relationship between the function of a sequence specific domain and RNA-protein function. This can be achieved by expressing a mutant RNA containing an RNA aptamer sequence (e.g., MS2 or BoxB) that can interact with the protein of interest through an engineered protein tag (e.g., MCP or $\lambda \mathrm{N}$ ) (Keryer-Bibens et al. 2008). Although this approach was critical for defining the functions of several Xist domains (Chen et al. 2016; Pintacuda et al. 2017), it generally requires knowledge of the protein binding sites on a lncRNA.

\subsection{Posttranscriptional Degradation}

A more direct way to determine whether a lncRNA acts directly as an RNA molecule is to degrade the mature RNA after it is fully transcribed. There are several approaches for doing this, including antisense DNA oligonucleotides (ASOs) that anneal to the lncRNA and trigger RNase $\mathrm{H}$-mediated degradation (Liang et al. 2017) and RNA interference (RNAi) in which an antisense RNA anneals to 


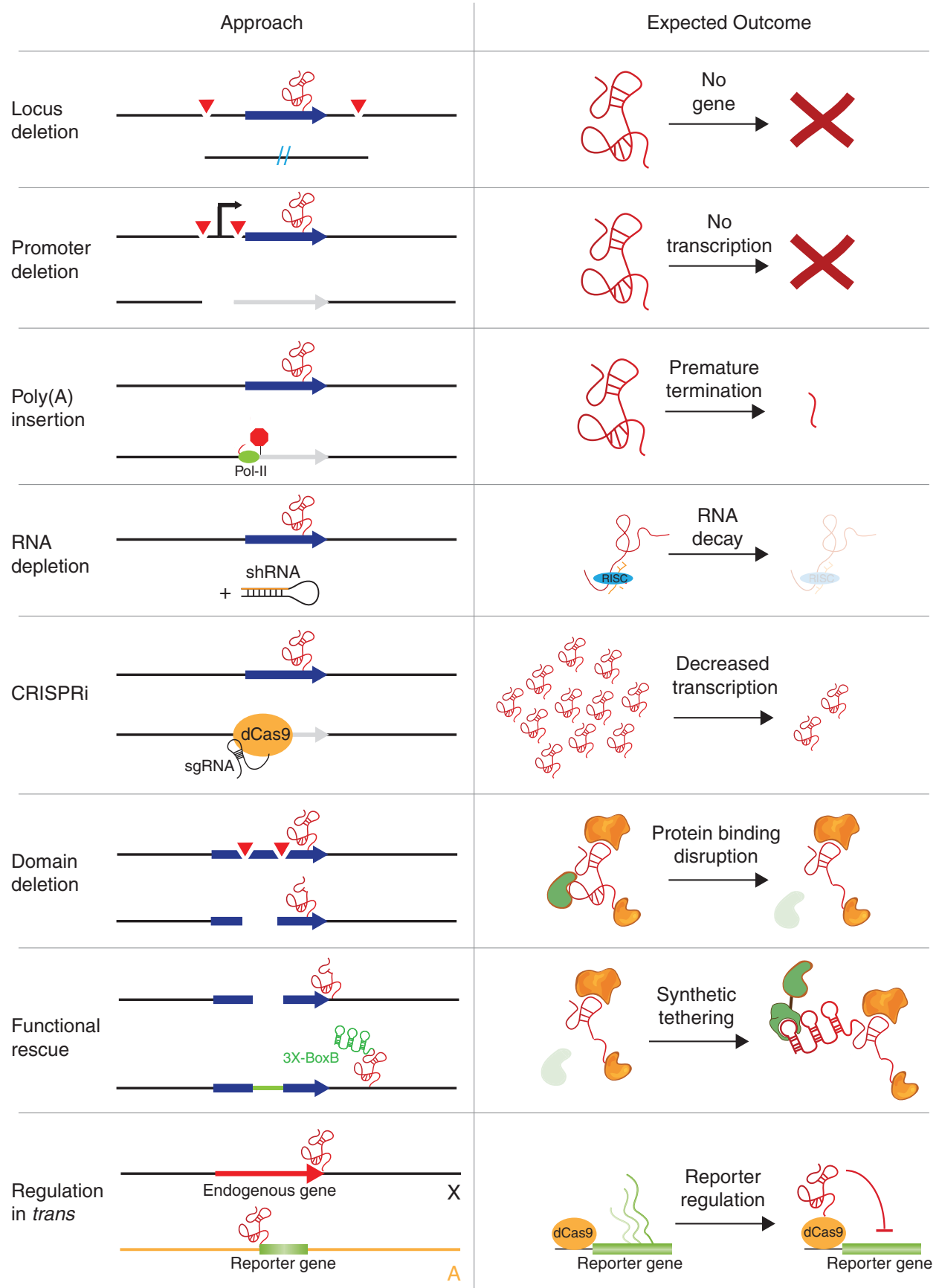

Figure 1. Genetic strategies to study long noncoding RNA (lncRNA) function. Locus and promoter deletions (e.g., by CRISPR [red arrows]) can generate null alleles such that the gene that encodes the lncRNA is removed from the genome or the promoter is removed preventing lncRNA transcription. However, both of these approaches could also delete functional regulatory DNA sequences contained within these DNA sequences. Inserting a poly(A) transcription termination signal does not disrupt transcription initiation at the lncRNA locus but terminates transcription prematurely. Antisense oligonucleotides or RNA interference (RNAi) can degrade the lncRNA posttranscriptionally, but there may be off-target effects that are often hard to predict. Recruitment of dCas9 (usually fused to a repressor domain such as KRAB) by short guide RNAs using CRISPR leads to decreased transcription of the lncRNA without mutating the DNA sequence, but because it also precludes recruitment of PolII to enhancer elements, it can also impact functions mediated through DNA elements. Deleting a specific lncRNA-protein interaction domain can impact protein binding and can be complemented with synthetic rescue experiments that tether the protein to the mutant RNA. Expressing a cis-acting lncRNA from a different locus and chromatin context can reveal mechanisms of action and gene regulatory function in trans. 
the lncRNA and triggers argonaute-mediated degradation (Ghildiyal and Zamore 2009). Although these represent important methods, in practice they are often less precise than genetic engineering because hybridization of these short oligonucleotide sequences can have off-target effects that are difficult to identify. Indeed, several lncRNAs that were initially characterized using RNAi, ASOs, or similar methods, have recently been reevaluated by genetic studies and shown to have distinct functions from those previously reported. These include several examples that have since been shown to act as cis-regulatory elements rather than functional RNA molecules (Engreitz et al. 2016a; Groff et al. 2016). For example, lincRNA-P21 was initially described as acting in trans based on functions identified by RNAi-mediated depletion of the lncRNA (Huarte et al. 2010). However, subsequent perturbation of this lncRNA using genetic dissection suggested that the RNA product may be dispensable and the observed phenotype may simply be explained by the cis-regulatory function of the DNA element (Groff et al. 2016). Indeed, several lncRNAs previously defined to contain functional roles based on RNAi in embryonic stem cells (ESCs) (Guttman et al. 2011) have been shown to have functions that occur in cis, independent of their RNA products (Engreitz et al. 2016a). Although these results do not exclude the possibility that these RNA products may still have other functional roles, they do highlight the importance of orthogonal approaches and validation to directly confirm the functional role of a lncRNA.

Although the individual approaches above have caveats regarding their interpretation, when performed in combinations they can provide high confidence about the function of a lncRNA. One orthogonal approach to gain additional confidence is to complement genetic perturbation with a rescue construct in trans. This may often fail, however, because many lncRNA functions are associated with $3 \mathrm{D}$ proximity and therefore simply expressing the lncRNA from an exogenous site may fail to rescue the defect. Other approaches, such as targeted recruitment of a IncRNA to a genomic DNA locus, or rescue of individual RNA-protein interactions, can overcome this issue, but requires more precise knowledge of the mechanisms by which a lncRNA may work. Recently, several new technologies have been developed that enable the direct assessment of the functional role of a lncRNA through targeted recruitment of the lncRNA in trans to a reporter gene. These approaches have been used for studying HOTAIR by recruitment through the GAL4-UAS system (Portoso et al. 2017). More recently, a method called CRISPRDisplay has generalized this approach in a manner that enables programmable recruitment of $\ln \mathrm{R} R \mathrm{NAs}$ to different DNA regions on larger scales (Shechner et al. 2015).
Because these approaches recruit a lncRNA independently of its transcriptional and local environment, presence of a function in these assays indicates a role for the RNA transcript itself. However, the absence of a phenotype in such an assay does not preclude a critical role for the lncRNA in its endogenous chromatin environment, which may be distinct from the chromatin context that is present at the reporter gene.

\section{DEFINING IncRNA-PROTEIN INTERACTIONS AND THEIR FUNCTIONAL CONTRIBUTIONS}

Determining how Xist mediates transcriptional silencing required advances in biochemical purification approaches and mass spectrometry to comprehensively define the proteins that directly interact with Xist (Chu et al. 2015; McHugh et al. 2015). These studies identified numerous proteins that begin to explain key aspects of how Xist works to orchestrate the process of XCI. Mapping in which these proteins bind across the Xist lncRNA showed that they bind at discrete locations (Chen et al. 2016; Chu et al. 2015; Cirillo et al. 2016; Pintacuda et al. 2017) and enabled genetic studies to delete individual domains to study the functional contribution of each IncRNA-protein complex in orchestrating XCI. Together, these studies uncovered the Xist-protein interactions that are required for transcriptional silencing, recruitment of various chromatin regulators (e.g., PRC1 and PRC2), localization to genomic DNA, and chromosome-wide spreading.

In this section, we will discuss methods for defining (1) which proteins interact with a lncRNA, (2) where on the RNA each of these proteins binds, and (3) the functional role of each lncRNA-protein interaction. We will highlight important issues and consideration that are needed for designing and interpreting lncRNA-protein interactions.

\subsection{Methods for Comprehensively Defining Proteins That Bind to a Specific IncRNA}

There are several methods for purifying a specific lncRNA and defining associated proteins. These methods differ in how the RNA is purified after incubation with proteins in solution or after cross-linking of RNA-protein complexes in vivo.

One general approach for purifying RNA is to attach an RNA sequence that forms a tight interaction with a defined protein complex. For example, a hairpin structure from the MS2 RNA forms a tight interaction with the bacteriophage MS2 viral coat protein (Keryer-Bibens et al. 2008). In this approach, repeats of the MS2-binding RNA are attached to an RNA of interest and the RNA is captured by immobilizing the associated RNA onto a protein-bound 
resin. There are many variants of this approach using different combinations of RNA-protein substrates that have various affinities and therefore enable different stringencies (McHugh et al. 2014). In addition, there are variants such as the S1 RNA aptamer that mimics biotin in that it can interact directly with streptavidin. Because it has a lower affinity than biotin, it can be selectively eluted through the addition of free biotin (Srisawat and Engelke 2002). This specific elution strategy provides important benefits for reducing the background, and other similar approaches have been developed for this reason. For example, the Csy4 protein, derived from the bacterial CRISPR system, binds tightly to its cognate RNA, more tightly than MS2 or PP7 coat protein interactions, while enabling specific elution through the addition of imidazole (Lee et al. 2013).

The other general approach for RNA purification is based on hybridization of antisense oligonucleotides (Chu et al. 2011; Engreitz et al. 2013; Simon et al. 2013; Rogell et al. 2017). These approaches generally use biotin labeled oligonucleotides to hybridize to a specific RNA sequence and capture it, and its associated proteins, from a complex mixture. These strategies vary in several ways: (1) some use individual oligonucleotides (Simon et al. 2013; Rogell et al. 2017) whereas others use pools of oligonucleotides that tile across the RNA of interest (Chu et al. 2011; Engreitz et al. 2013); (2) some methods use short oligonucleotides (Chu et al. 2011; Simon et al. 2013; Rogell et al. 2017) and others use long oligonucleotides (Engreitz et al. 2013); and (3) some use unmodified nucleotides ( $\mathrm{Chu}$ et al. 2011; Engreitz et al. 2013; Simon et al. 2013), whereas others use locked nucleic acids (Rogell et al. 2017). The key consideration in choosing between these parameters comes down to specificity of the hybrid and the stringency of the purification conditions used in the purification procedure.

Until recently, these RNA purification approaches were generally performed after incubating a labeled RNA with protein obtained from total cell extracts. Although such an approach had proven successful for defining proteins that interact with classical noncoding RNAs (ncRNAs) (such as snRNPs and 7SK), they proved more problematic for studying lncRNAs. For example, early attempts to purify Xist and its associated proteins used an affinity tag coupled to the RNA (Brown and Baldry 1996) to identify an interaction between Xist and heterogeneous nuclear ribonucleoprotein C (hnRNPC); yet, this interaction was insufficient to explain the silencing role mediated by Xist. Similar approaches led to the detection of specific proteins that interact with several lncRNAs (e.g., NORAD, linc-P21) (Huarte et al. 2010; Lee et al. 2016), but they are usually limited to identifying abundant RNA binding proteins (e.g., Pumilio, heterogeneous nuclear ribonucleoprotein $\mathrm{K}$ [hnRNPK]) and do not provide a comprehensive picture of the proteins that interact with a lncRNA.

These results highlight one of the key challenges with RNA purification methods that are performed in solution: Many biologically relevant RNA-binding proteins (RBPs) that interact with a lncRNA are not identified. The issue is that when incubated in solution, abundant RBPs can outcompete lower abundance proteins. Thus, it is easier to observe interactions with abundant RBPs, but not necessarily other bona fide RBPs that interact with the lncRNA in cells, which may be present at much lower concentrations. This is true even if specific RBPs have significantly higher affinity because the differences in concentration are often large enough to overcome differences in affinity. Moreover, because these approaches break open the cell, such that the concentrations of proteins are uniform throughout solution, the results may not accurately reflect the actual local concentration of protein complexes near an lncRNA in vivo (Darnell 2010; Mili and Steitz 2004; McHugh et al. 2014). Consequently, promiscuous RNAprotein interactions might form in vitro that do not occur in vivo, because of compartmentalization, sequestration, and phase separation. Accordingly, despite numerous attempts to define the mechanism of how Xist silences transcription, until recently it remained unclear what RBPs interact with Xist and what components are required for Xist-mediated transcriptional silencing.

To address this challenge, several groups developed RNA purification methods (e.g., ChIRP-MS, CHART-MS, and RAP-MS) (Fig. 2) that can both comprehensively define the proteins that interact with a specific lncRNA and at the same time achieve the specificity required to only identify interactions that occur in vivo (West et al. 2014; Chu et al. 2015; McHugh et al. 2015). These methods achieve this goal by using in vivo cross-linking to fix RNA-protein interactions that occur inside cells and then purifying the RNA of interest using extremely stringent, even denaturing, conditions to remove background associating proteins. These methods differ in the type of cross-linking that is used to fix RNA-protein interactions, which impacts the types of proteins that are identified by each method. For example, RAP uses ultraviolet (UV) cross-linking to fix only those proteins that directly interact with an RNA, whereas ChIRP uses formaldehyde cross-linking which also cross-links interacting proteins. After purification, proteins that are covalently cross-linked to a given RNA are identified using mass spectrometry.

These approaches led to the discovery of dozens of proteins that interact with Xist. Although there are differences between the proteins identified by these approaches, the proteins identified using UV cross-linking would be expected to represent proteins that directly interact with 
A

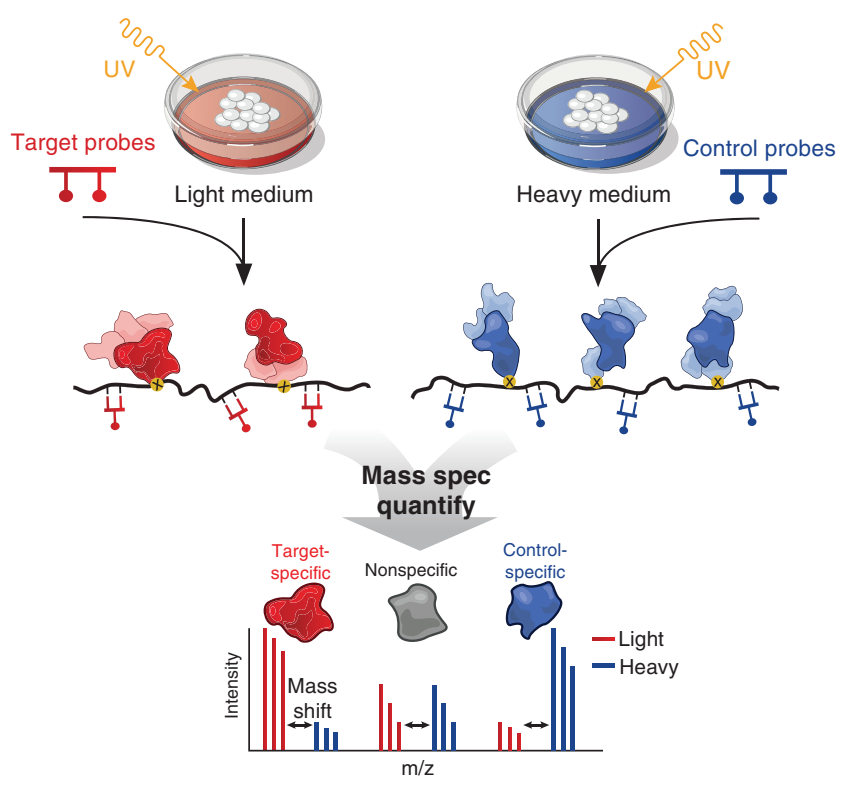

B
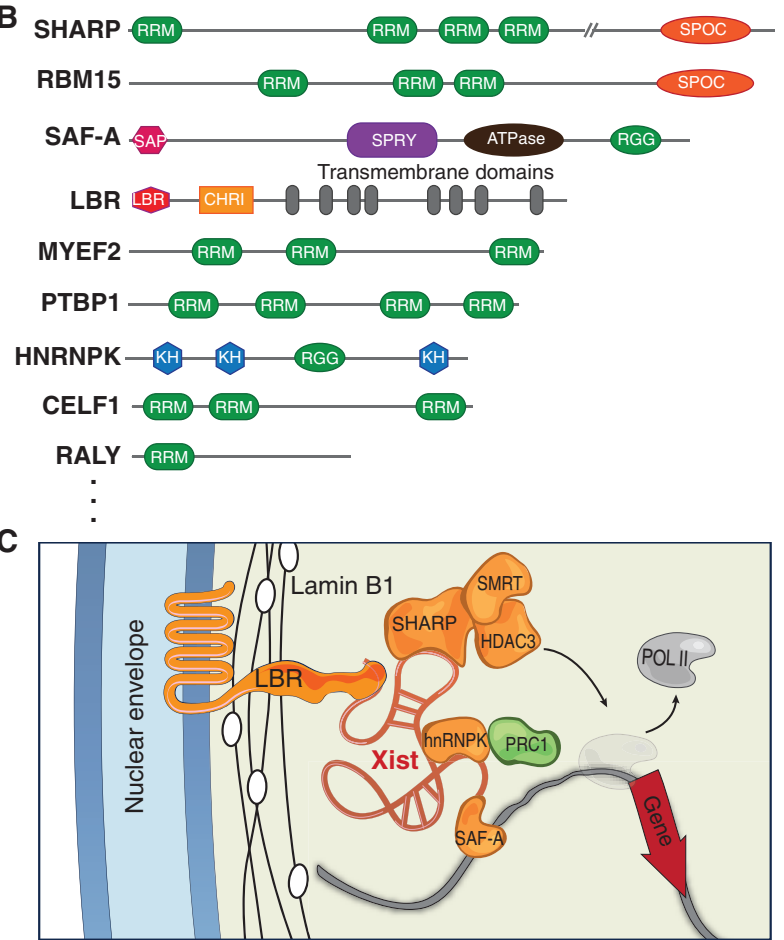

Figure 2. Comprehensive identification of proteins that interact with long noncoding RNAs (lncRNAs). (A) Antisense capture probes are hybridized to the target lncRNA in cross-linked lysate that has been SILAC-labeled with heavy or light amino acids. Following capture and stringent washes, the purified proteins are identified using mass spectroscopy. Nonspecific background peptides found in the control sample are subtracted out, identifying specific interacting proteins. $(B)$ Example list of Xist-interacting proteins found by multiple Xist purification and mass spectrometry (MS) methods, and their associated protein domains. (C) Current model for how Xist interacts directly and indirectly with proteins in the cell to silence transcription on Xi, revealed by recent MS studies. Xist RNA associates with genomic DNA through a direct interaction with SAF-A/hnRNPU, and binds SHARP/SPEN to recruit SMRT and HDAC3 to deacetylate histone H3 and exclude RNA polymerase II from nearby loci. Xist also binds hnRNP-K which recruits the PRC1 complex, leading to histone ubiquitination and subsequent recruitment of the PRC2 complex and its H3K27me3 histone methyltransferase activity. Lamin B receptor (LBR) binding of Xist recruits $\mathrm{Xi}$ to the nuclear lamina, creating a repressive nuclear territory and enabling further spreading by Xist. Proteins depicted as directly touching Xist RNA in this figure were identified by MS studies as directly bound to Xist; the other proteins depicted were subsequently identified by orthogonal studies. (Adapted, with permission, from McHugh et al. 2015.)

an RNA, whereas those identified by formaldehyde would also include proteins that associate with an RNA via protein-protein interactions. Importantly, the core protein components identified are similar between both methods (Fig. 2) (Chu et al. 2015; McHugh et al. 2015).

Cross-linking studies identified the proteins that explain eviction of RNA polymerase II and transcriptional silencing of the X chromosome. Specifically, numerous analyses identified SHARP (also known as SPEN) as a direct Xistinteracting protein that is required for chromosome-wide transcriptional silencing on the $\mathrm{X}$ chromosome (Chu et al. 2015; McHugh et al. 2015; Moindrot et al. 2015; Monfort et al. 2015). Determination of the extended protein complex interacting with SHARP revealed an essential role for SMRT and HDAC3 in the exclusion of RNA polymerase
II from the X-chromosome territory and subsequent transcriptional silencing (McHugh et al. 2015). These results indicated that Xist initiates transcriptional silencing by directly binding to SHARP, recruiting SMRT and HDAC3 to trigger deacetylation on the $\mathrm{X}$ chromosome. Additionally, these studies identified hnRNPK as a direct Xist-interacting protein (Chu et al. 2015; Pintacuda et al. 2017). Analysis of the extended interaction network showed that hnRNPK acts to recruit the PRC1 complex to the X chromosome through the noncanonical PCGF3/5 complex (Pintacuda et al. 2017). This leads to ubiquitylation of chromatin and subsequent recruitment of PRC2 and its associated H3K27me3 modifications across the X chromosome (Almeida et al. 2017), thus reconciling prior observations that PRC2 is recruited to Xi but is not recruited through a direct 
interaction between PRC2 and the Xist RNA. These studies also identified SAF-A (also known as heterogeneous nuclear ribonucleoprotein $\mathrm{U}$ [hnRNPU]) and showed that this interaction is required for tethering the Xist RNA to genomic DNA sites on the X chromosome (Hasegawa et al. 2010; Chu et al. 2015; McHugh et al. 2015). Finally, these studies identified the lamin B receptor (LBR) and showed that this interaction is required for enabling Xist to spread across the X chromosome (McHugh et al. 2015; Chen et al. 2016). Specifically, the Xist-LBR interaction is required for recruiting the $\mathrm{X}$ chromosome to the nuclear lamina and by doing so leads to three-dimensional (3D) structural changes on the $\mathrm{X}$ chromosome that allow Xist to spread to additional DNA sites (Chen et al. 2016).

Importantly, the ability to comprehensively define the proteins and complexes that interact with Xist provided the first insights into the mechanisms by which Xist orchestrates XCI. Yet, despite advances in methods for purifying a lncRNA, these methods have been applied only to a relatively small number of lncRNAs because they remain technically challenging. Specifically, (1) most of these tools are limited to studying relatively highly abundant lncRNAs (i.e., Xist, Malat1) and accordingly do not work well for the vast majority of IncRNAs; (2) these methods often require large numbers of cells, limiting their usage to cell types that can be easily grown in culture; and accordingly will not work for primary cells used for studying human disease, and (3) these methods often require extensive optimization for each lncRNA and thus are not amenable to systematic characterization of many lncRNAs. Future work will be needed to adapt these approaches to enable greater sensitivity and scalability for studying a larger number of lncRNAs across broader contexts.

\subsection{Mapping IncRNAs That Interact with Specific Proteins}

To overcome the limitation in detection sensitivity imposed by RNA-centric purifications, attempts were made to use information about XCI to guide identification of the proteins that might be involved. One important discovery was that the process of $\mathrm{XCI}$ is associated with recruitment of the PRC2 complex and its associated H3K27me3 marks across the $\mathrm{X}$ chromosome (Plath et al. 2003). Based on this observation, the interaction between Xist and PRC2 was tested using RNA immunoprecipitation (RIP) experiments. RIP uses native purification conditions in cross-linked or noncross-linked cells to immunoprecipitate proteins and measure their associated RNAs (Zhao et al. 2008). Indeed, an interaction between Xist and PRC2 was shown to occur using these methods. Moreover, PRC2 was shown to interact with a truncated Xist RNA that just contained the
A-repeat region of Xist (Zhao et al. 2008), the RNA region required for transcriptional silencing (Wutz et al. 2002). These observations led to a model whereby Xist directly binds to PRC2 and recruits this repressive chromatin complex to the $\mathrm{X}$ chromosome to mediate transcriptional silencing (Zhao et al. 2008).

More generally, observation of an interaction between Xist and PRC2 led to intense study of the PRC2 complex as an RNA binding protein, with recent studies arguing that PRC2 binds to hundreds of different lncRNAs. This insight led to the proposal that lncRNAs act to recruit PRC2 to genomic DNA targets, among other roles (Khalil et al. 2009; Zhao et al. 2010; Guttman et al. 2011).

Although this result seemed to indicate a potential mechanism for how Xist-mediated transcriptional silencing might occur, several subsequent observations are incompatible with this model. Specifically, deletion of PRC2 components that prevent its recruitment to the $\mathrm{X}$ chromosome have no impact on Xist-mediated transcriptional silencing (Kalantry and Magnuson 2006; Schoeftner et al. 2006) and deletion of the A-repeat from Xist does not preclude PRC2 recruitment to the $\mathrm{X}$ chromosome (Plath et al. 2003; Kohlmaier et al. 2004; da Rocha et al. 2014; McHugh et al. 2015). Moreover, the distance between Xist and PRC2 on the inactive $\mathrm{X}$ chromosome as measured by super-resolution microcopy appears to be incompatible with direct binding (Cerase et al. 2014). In addition, recent studies purifying Xist using denaturing conditions failed to identify an interaction between Xist and any of the PRC2 components in vivo (Chu et al. 2015; McHugh et al. 2015; Minajigi et al. 2015). Instead, these studies identified other RBPs that directly bind to Xist, and are essential for PRC2 recruitment across the X chromosome. Furthermore, it is now clear that PRC2 is also dispensable for the functions of other IncRNAs, including HOTAIR, which it had been previously reported to bind (Portoso et al. 2017).

This discrepancy between the biochemical evidence supporting lncRNA-PRC2 interactions, and functional evidence showing that PRC2 is dispensable for Xist function, highlight important considerations for studying lncRNAprotein interactions. Specifically, interactions that are observed using immunoprecipitation methods do not necessarily reflect interactions that occur in vivo, but could instead reflect those that form in solution after cell lysis. Indeed, in a classic experiment, Mili and Steitz showed that immunoprecipitation methods can indeed identify RNA-protein interactions that do not occur in vivo, but rather form in solution after lysis (Mili and Steitz 2004). Consistent with this explanation, several recent in vitro experiments have shown that PRC2 components bind with high affinity to all RNAs, including bacterial RNAs 
(Davidovich et al. 2013), suggesting that detecting their interactions with Xist-and possibly other lncRNAsmay represent high-affinity associations that may not be functionally required.

To date, most studies of IncRNA-protein interactions have used RIP, which has led to reports of numerous additional chromatin complexes that interact with various lncRNAs (Guttman et al. 2011). Accordingly, these same considerations must be taken into account when exploring the functional relevance of these interactions.

To account for the limited stringency afforded by the RIP method, the cross-linking and immunoprecipitation (CLIP) method was developed (Darnell 2010). CLIP uses UV cross-linking to form covalent interactions inside cells between directly interacting RNA and protein, followed by purification using more stringent wash conditions (i.e., $1 \mathrm{M}$ salt) and subsequent separation through a denaturing gel and transfer to a nitrocellulose membrane to enrich for in vivo cross-linked RNA-protein interactions (Fig. 3A) (Darnell 2010). Importantly, the key difference between RIP and CLIP is the stringency of the wash conditions and denaturing gel separation used rather than the cross-linking itself. In fact, RIP can be performed in UV cross-linked cells, but does not achieve the same stringency as CLIP without incorporating the purification of RNA-protein complexes from a denaturing gel. Because of this increased stringency, CLIP methods have emerged as the gold-standard for defining in vivo RNA-protein interactions.

Despite the critical advantages of the CLIP method, simply observing sequencing reads in a CLIP experiment does not necessarily indicate an in vivo RNA-protein interaction, and careful controls need to be designed, especially when studying proteins that may not bind RNA or that may bind to only a few RNAs in vivo.

\subsection{Methods for Mapping the Precise Protein Binding Sites on RNA}

CLIP also enables the identification of the direct RNA binding site of a protein-a necessary prerequisite for functional characterization of IncRNA-protein interactions. CLIP entails controlled RNase digestion of RNA into small fragments before immunoprecipitation of the protein. Accordingly, the only RNA fragment that will be purified is the region that is directly cross-linked to the protein of interest. Although this approach hones in on the region of the RNA
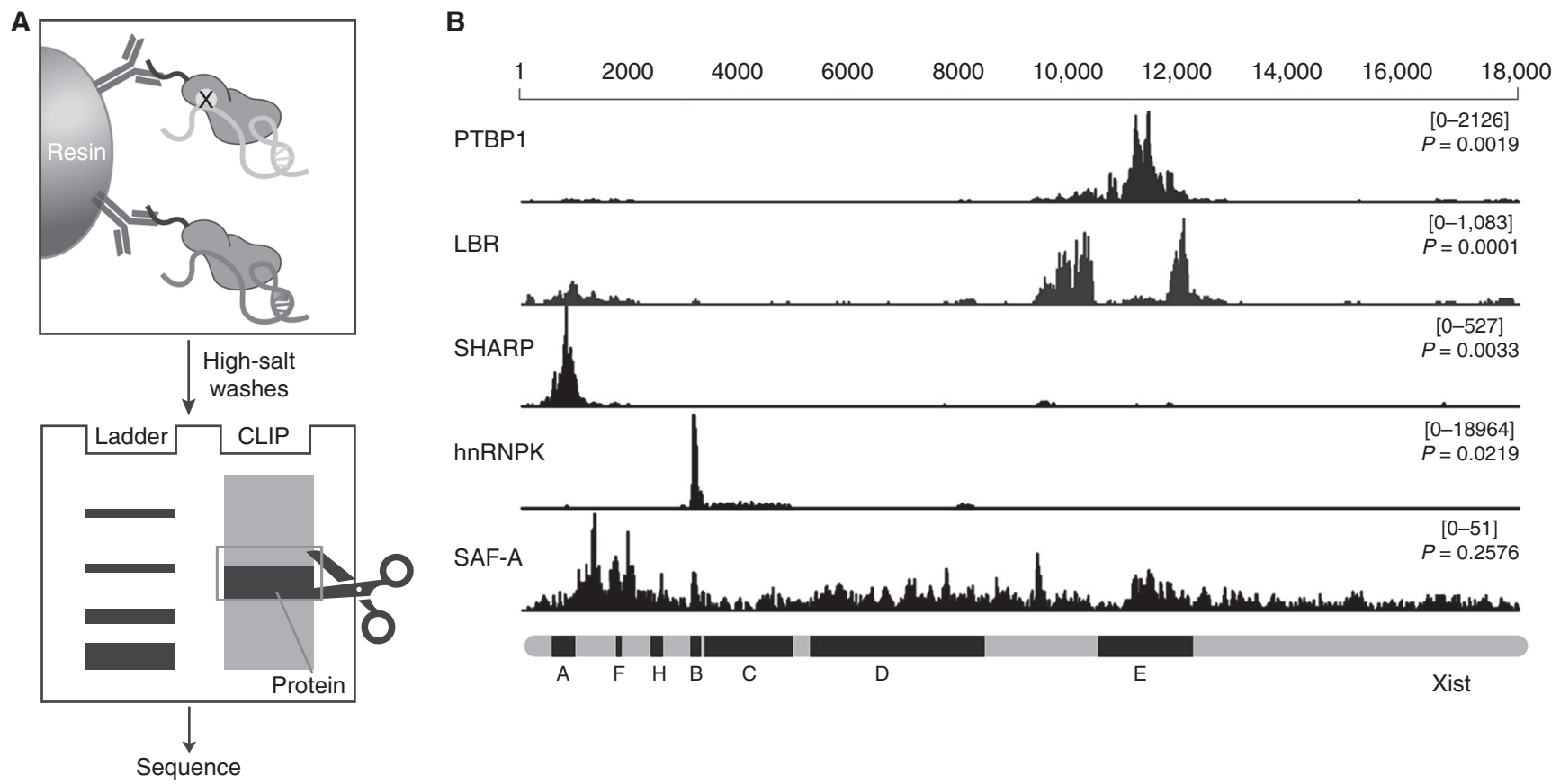

Figure 3. Cross-linking and immunoprecipitation (CLIP) methods identify protein binding sites on long noncoding RNAs (lncRNAs). (A) An overview of the CLIP method. RNA-protein interactions are cross-linked using ultraviolet (UV) light (depicted by $\mathbf{x}$ ). Purification and stringent washes are followed by gel extraction of cross-linked RNAprotein complexes, and the purified RNA fragments are sequenced. (B) Example of protein interaction domain identification on Xist by CLIP (Cirillo et al. 2016). Although SAF-A/hnRNP-U has a broad binding distribution on Xist, other interacting proteins have clearly defined binding domains. (B, From Cirillo et al. 2016, adapted, with permission.) 
that is bound by a protein, it does not resolve the precise nucleotides that are bound by a protein. To surmount this problem, several groups have developed adaptations of the CLIP method that more accurately resolve the sites of interaction. Although several such methods have been developed, one of the most popular strategies takes advantage of the fact that UV cross-linking creates an irreversible RNAprotein linkage, producing a peptide adduct present on the purified RNA after immunoprecipitation. Because reverse transcriptase often pauses at these adducts, the locations of the resulting truncated cDNA products can be mapped using sequencing to identify the likely cross-link sites (Konig et al. 2010).

CLIP has been successfully used to define the precise RNA binding sites of numerous RNA binding proteins (Darnell 2010), including those of several on Xist (Fig. 3B) (Chen et al. 2016; Cirillo et al. 2016). For example, mapping the SHARP protein by CLIP showed that it binds to the highly-conserved A-repeat domain of Xist, the domain that was previously shown to be required for transcriptional silencing (Chu et al. 2015; Chen et al. 2016). Interestingly, CLIP studies of hnRNPK showed that it interacts specifically with the B-repeat region of Xist (Cirillo et al. 2016; Pintacuda et al. 2017), a domain that was previously showed to be required for PRC2 recruitment to the X chromosome (da Rocha et al. 2014). CLIP studies of LBR identified three distinct sites on the Xist RNA, including a region overlapping the A-repeat deletion (Chen et al. 2016; Cirillo et al. 2016). Interestingly, the interaction between Xist and LBR appears to require each of the individual sites, suggesting that these regions interact to form a higher-order structured region of the RNA (Chen et al. 2016). Finally, CLIP studies of SAF-A showed that it binds to many regions across the Xist lncRNA and appears to recognize the RNA in a promiscuous manner, lacking precise sequences or structural recognition motifs (Cirillo et al. 2016). This is consistent with recent in vitro studies showing that the RGG domains of SAF-A bind broadly to many different RNA sequences (Ozdilek et al. 2017).

These different binding patterns can provide functional and mechanistic insights into how these RBP complexes work. For example, in the case of SAF-A, which appears to bind broadly across the Xist RNA, many interactions between Xist and SAF-A may lead to high-avidity interactions that create a tight interaction of the Xist lncRNA with chromatin.

Importantly, all of these biochemical measurements represent an average profile of interactions occurring across millions of cells and do not provide information about whether these interactions occur simultaneously with a single RNA molecule. Novel methods will be needed to determine the structures and stoichiometries of these complexes, such information will provide critical new insights into lncRNA mechanisms.

\subsection{Methods for Studying the Function of Individual IncRNA-Protein Interactions}

There are several approaches to defining the function of a lncRNA-protein interaction. For example, targeted deletion of the RNA binding site that is recognized by a protein enables studies of the specific RNA-protein interaction without impacting other roles that an RNA binding protein might play. Indeed, this approach was used to study the Xist interactions with SHARP, LBR, and hnRNPK (Chen et al. 2016; Almeida et al. 2017; Pintacuda et al. 2017). However, this method only works when there is a clearly defined binding site for a protein on the lncRNA. If a protein binds broadly across an RNA, such as SAF-A on Xist, targeted mutagenesis of the RNA will not work. In such cases, deletion of the RNA binding domain of the protein can also be used to disrupt this interaction. However, in this case, the mutation will also impact the interaction between the RBP and other RNAs with which it might associate.

Importantly, in this mutagenesis approach, any observed phenotypes can be confirmed by performing rescue experiments in which the RBP and RNA are tethered together independently to determine if their interaction can explain the observed phenotype. For example, a mutant RNA (lacking a protein binding site) can be fused to the BoxB RNA apatamer and coexpressed with the protein containing a $\lambda \mathrm{N}$ peptide that will tightly bind to BoxB. In this case, if the deleted domain is critical for explaining a phenotype because of the interacting protein, then the synthetic rescue should no longer show this observed phenotype. This approach was used to show the essential role of LBR in enabling Xist spreading (Chen et al. 2016), RBM15 in recruiting YTHDC1 (Patil et al. 2016), and in hnRNPK binding and recruiting PRC1 (Almeida et al. 2017; Pintacuda et al. 2017).

\section{METHODS FOR DETERMINING WHERE IncRNAs LOCALIZE}

Understanding how lncRNAs work requires a detailed understanding of what the direct targets of each lncRNA areincluding genomic DNA and RNA targets-and where in the cell these interactions occur. The subcellular localizations of $\operatorname{lncRNAs}$ provide some of the greatest clues about their biological roles and molecular functions. As functional molecules, lncRNAs must localize to their sites of action within the cell. For instance, a lncRNA that localizes to subnuclear compartments beyond its site of transcription could regulate gene expression or RNA biogenesis in trans, 
but is unlikely to be translated by ribosomes, whereas an exclusively cytoplasmic lncRNA would not be expected to have a direct role in altering transcription or chromatin structure, but instead might be involved in regulating proteins or other RNAs after they are produced. Moreover, the subcellular localization of lncRNAs can be a consequence of interacting with proteins, or they can recruit proteins to specific sites, structures, and territories to integrate functions or sequester molecules away from their targets.

Indeed, one of the earliest and most significant insights into Xist function was the visual observation that the Xist RNA localizes to a single chromosome in female cell nuclei, apparently coating the inactive X (Brockdorff et al. 1991; Brown et al. 1991; Clemson et al. 1996). It was this observation that led to the initial proposal that Xist acts through a functional lncRNA-not its protein productby spreading in cis across the chromosome from which it is expressed, to broadly silence transcription. Subsequent experiments in which Xist was integrated into autosomal regions (Lee et al. 1996; Herzing et al. 1997) showed that Xist similarly spreads across these autosomal regions, showing that the affinity of Xist RNA is not for particular DNA sequences but instead is related to the direct physical connection between the gene expressing Xist RNA and the DNA it binds. These observations established the core model for how the Xist RNA works. More recently, high-resolution mapping of Xist localization by molecular methods revealed in detail the underlying relationships of Xist spreading with 3D spatial proximity, chromatin structure, and the kinetics of gene silencing across X (Engreitz et al. 2013).

In this section, we will discuss the various methods for studying lncRNA localization within the cell (Fig. 4).

\subsection{Direct Visualization of IncRNAs by Microscopy}

Fluorescence microscopy has proven to be one of the most powerful tools for studying lncRNA localization, principally through fluorescence in situ hybridization (FISH) and immunofluorescence (IF). In FISH, fixed cells are hybridized with fluorescently labeled probes antisense to the RNA target and visualized by light microscopy. In fact, Xist was initially shown to localize to the Barr body at the nuclear periphery and to broadly coat the inactive $\mathrm{X}$ using FISH (Clemson et al. 1996). These observations directly linked the RNA molecule itself with the subnuclear territory of $\mathrm{X}$ inactivation. Importantly, these studies used probes that distinguished nascent Xist RNA-produced at the XICfrom the spliced, polyadenylated, mature Xist RNA that spreads over the chromosome. Subsequent FISH studies performed throughout development and in differentiating female ESCs observed the individual stages of Xist-induced silencing of X: initiation of Xist expression from the XIC on the presumptive $\mathrm{Xi}$, widespread localization of spliced Xist concomitant with propagation of inactivation in cis, comigration with the Xi to the nuclear periphery, and continued association with Xi throughout most of the cell cycle, even in the absence of continued Xist transcription. Immunofluorescence, wherein specific proteins in fixed cells are labeled using fluorescent antibodies, combined with Xist FISH, showed that Xist localization and spreading precedes hallmarks of transcriptional repression, such as histone deacetylation and methylation, DNA methylation, and exclusion of Pol II. These observations, when combined with genetic experiments described earlier in this review, strongly implicated the RNA itself as required for establishing $\mathrm{X}$ inactivation, even though the mechanistic details remained mysterious.

Improvements in microscopy and staining revealed subchromosomal enrichment of Xist RNA at gene-rich "G-light" bands on $\mathrm{Xi}$, and an apparently low affinity for gene-poor heterochromatic regions (Duthie et al. 1999), with spreading into active gene regions requiring the Arepeat domain (Wutz et al. 2002), leading to the model that Xist initially localizes to high-affinity sites before spreading to the rest of the chromosome. Recently, superresolution 3D structured illumination microscopy (3DSIM) of the Xi confirmed that Xist RNA initially localizes to discrete foci before chromatin compaction, followed by spreading to occupy discrete chromatin domains in close association with the nuclear matrix protein SAF-A (previously shown to be required for Xist association with the Xi [Hasegawa et al. 2010]) and preceding Pol II exclusion but not involving repressive chromatin modifications, such as H3K27me3 (Cerase et al. 2014).

\subsection{Methods for Genome-Wide Mapping of IncRNA Localization}

Although imaging provided key insights into how Xist works, these approaches could not define where an RNA binds to genomic DNA at high resolution. Accordingly, it was still unclear how Xist spread across the X chromosome on initiation of XCI.

Recently, several methods to map lncRNA localization at high resolution using antisense purification coupled with sequencing of genomic DNA have been developed. These methods take advantage of labeled antisense probes to $\mathrm{pu}$ rify target RNAs from cross-linked cell lysates and identify DNA or RNA interactions by sequencing (Chu et al. 2011; Engreitz et al. 2013; Simon et al. 2013), an approach that is conceptually similar to the ChIP-seq method used for mapping protein-DNA interactions. Indeed, the use of different cross-linking agents, such as formaldehyde or pso- 

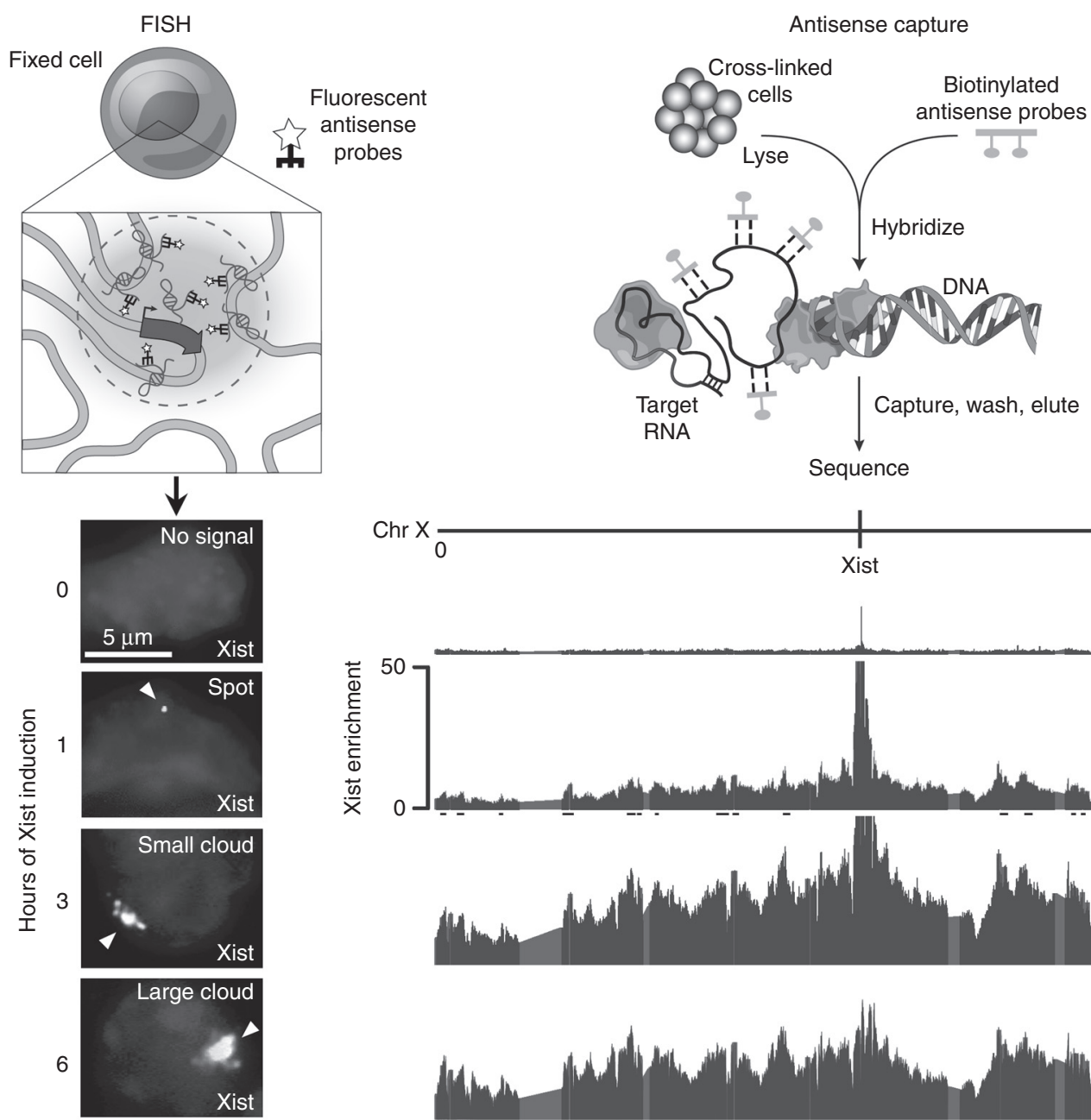

Figure 4. Methods to study long noncoding RNA (lncRNA) localization. Fluorescence in situ hybridization (FISH) has proven to be a powerful and general method to understand lncRNA localization. In this method, fluorescent antisense probes are hybridized to RNA targets in fixed cells and visualized using fluorescence microscopy. Shown on the left by FISH is the Xist RNA cloud coating the Xi after Xist induction. However, the resolution provided by this method is limited to relatively coarse observations. Depicted on the right is the same Xist induction time course assayed by RNA antisense purification (RAP) of Xist RNA using biotinylated antisense probes and sequencing of the bound X chromosome DNA. Such methods revealed that Xist exploits the 3D structure of the X chromosome to initially bind sites spatially proximal to the Xist locus and then spread to nearby active regions. (From Engreitz et al. 2013, adapted, with permission.)

ralen, enables the mapping of different interaction types, including protein-mediated RNA localization and direct nucleic acid hybridization (Engreitz et al. 2014).

Application of these methods to map Xist interactions with chromatin shed new light on how Xist spreads across the X chromosome during XCI in inducible Xist cell lines and female ESCs (Engreitz et al. 2013; Simon et al. 2013). These studies identified discrete and linearly distal sites on the Xi where the Xist RNA first localizes before spreading broadly across the $\mathrm{X}$ chromosome. Interestingly, the initial Xist localization sites lack enrichment for specific sequence motifs or chromatin modifications. Instead, comparison to high-throughput chromatin conformation capture (Hi-C) interaction data revealed a striking relationship between the initial Xist binding sites and DNA regions that are in close $3 \mathrm{D}$ physical proximity to the XIC in the nucleus. This observation led to the model that Xist exploits 3D chromosome conformation, rather than specific high-affinity sequences, to identify its initial target sites on the Xi. In fact, determining the localization of Xist when it is expressed from a transgene located on a distinct region of the $\mathrm{X}$ chromosome showed that the RNA then localized at sites that were closest in $3 \mathrm{D}$ proximity to the transgene integration site-displaying an entirely distinct pattern of locali- 
zation from that observed when Xist was expressed from its endogenous locus (Engreitz et al. 2013).

These genomic mapping tools were also essential for uncovering how Xist spreads from its site of transcription to other sites on the Xi. Specifically, Xist spreads from its initial target sites to more distal sites on the $\mathrm{X}$ chromosome. This spreading to actively transcribed regions on the X chromosome requires the A repeat region of Xist (Chaumeil et al. 2006; Engreitz et al. 2013; Chen et al. 2016), a region that is necessary for transcriptional silencing (Wutz et al. 2002). These studies revealed that Xist initially localizes to DNA regions that most frequently contact the Xist genomic locus in 3D proximity (Engreitz et al. 2013). At each of these sites, Xist interacts with the nuclear matrix protein SAF-A, which provides the physical link that tethers the Xist lncRNA to genomic DNA (McHugh et al. 2015). One of the most striking architectural changes associated with the induction of Xist is the repositioning of the entire $\mathrm{Xi}$ adjacent to the nuclear lamina. Recent proteomic studies have revealed that Xist directly interacts with lamin B receptor (LBR), and disruption of the Xist-LBR interaction leads to defective recruitment of the $\mathrm{X}$ to the lamina, as well as preventing Xist from spreading (McHugh et al. 2015; Minajigi et al. 2015). These results showed that Xist interacting with LBR leads to a change in chromosome architecture and enables Xist spreading from its site of transcription to other sites on the Xi (Engreitz et al. 2013; Chen et al. 2016).

Although these methods have provided critical insights for studying lncRNAs, there are still many important issues that need to be taken into account when interpreting the data. Specifically, capture of any RNA will enrich its transcribed DNA locus and accordingly, it is extremely challenging to discriminate between IncRNA interactions that occur in cis from those that simply reflect nascent transcription. In the case of Xist, this was addressed by using a doxycycline inducible promoter to perform a pulse-chase experiment and prevent nascent transcription of Xist before mapping its localization, ensuring that the DNA sites identified accurately represented the IncRNA targets (Engreitz et al. 2013). Given that many lncRNAs are thought to act in cis, future work is required to develop more generally applicable solutions that address this challenge directly.

\subsection{How Localization Provides Insights into IncRNA Mechanisms}

These same microscopy and sequencing approaches have been used to study the localization of other lncRNAs and derive key insights into their mechanisms.

For example, FISH experiments revealed that the imprinting lncRNAs Air (Nagano et al. 2008) and Kcnqlot1 (Terranova et al. 2008) accumulate along the chromosome near their sites of transcription only on the same allele, colocalizing with repressive chromatin modifiers and marks, suggesting that these RNAs may mediate repression of neighboring genes in cis. Conversely, FISH against the abundant highly conserved lncRNAs MALAT1 and NEAT1 revealed that they localize in many different nuclear sites corresponding to nuclear speckles and paraspeckles, respectively (Clemson et al. 2009; Mao et al. 2011). Sequencing studies showed that both Malat1 and Neat1 localize broadly to hundreds of transcribed DNA loci (Engreitz et al. 2014; West et al. 2014). In the case of Malat1, the lncRNA specifically associates with the nascent pre-mRNA at these sites and the interaction is rapidly abrogated on transcriptional inhibition (Engreitz et al. 2014; West et al. 2014). Finally, FIRRE was shown to accumulate over an $\sim 5 \mathrm{Mbp}$ region at its site of transcription on the $\mathrm{X}$ chromosome, and it also localizes to a number of seemingly distal autosomal sites. FISH on FIRRE showed that it concentrates in only one nuclear focus and that the trans targets are spatially organized within this nuclear compartment (Hacisuleyman et al. 2014). Despite these important insights derived from localization studies, it is still unclear what roles most of these lncRNAs play in organizing these precise locations within the nucleus (Engreitz et al. 2016b).

These examples highlight two strategies by which a lncRNA can localize in the nucleus-spatial proximity and affinity to targets. The balance between IncRNA localization through spatial proximity or DNA affinity may depend on the abundance of a lncRNA. For example, low-abundance lncRNAs may preferentially interact with regions that are in close proximity because they can attain high local concentration at these regions, whereas abundant lncRNAs may be able to diffuse through the nucleus to achieve high concentration at multiple target regions in trans. As an example, the HOTTIP IncRNA is expressed at low levels (about one copy per cell) and localizes in direct proximity to its transcription locus (Wang et al. 2011). In contrast, Malat1 is highly expressed (thousands of copies per cell) and can localize broadly to many different actively transcribed DNA regions throughout the nucleus (Engreitz et al. 2014; West et al. 2014). Although these IncRNAs represent examples of these respective localization strategies, other IncRNAs can integrate features of both strategies. For example, the roX2 lncRNA binds to specific DNA regions that are bound by the CLAMP protein, but does so preferentially at binding sites that are in close spatial proximity to its genomic locus (Soruco et al. 2013).

Although most well-studied lncRNAs accumulate in the nucleus, a number have been found in the cytoplasm, suggesting functions in posttranscriptional cellular processes. The most comprehensive lncRNA localization study to date used single-molecule FISH to examine the subcellular lo- 
calization and abundance of 61 lncRNAs in three cell types, and showed that nearly half exist in the cytoplasm (Cabili et al. 2015). Although cytoplasmic functions of lncRNAs are not well understood, a number of studies have used the methods described here to begin to describe the diverse roles IncRNAs can play in regulating cellular processes outside the nucleus. These include blocking posttranslational modifications on signaling proteins, acting as decoys for proteins and miRNAs, and regulating mRNA stability and translation (Rinn and Chang 2012; Engreitz et al. 2016b; Kopp and Mendell 2018).

\section{FUTURE DIRECTIONS: IncRNAs AND PHASE SEPARATION IN THE NUCLEUS}

An emerging theme from studies of Xist, Malat1, Neat1, Firre, and other lncRNAs is their role in organizing nuclear architecture. IncRNA expression creates a high local concentration near its site of transcription in 3D space, scaffolding the assembly of chromatin and RNPs into a structural domain (Fig. 5). Such domains could serve to locally coordinate shared regulatory processes (e.g., nucleoli, Cajal bodies, nuclear speckles) (Shevtsov and Dundr

$\substack{\text { IncRNA-mediated } \\ \text { compartment }}$
Examples

A

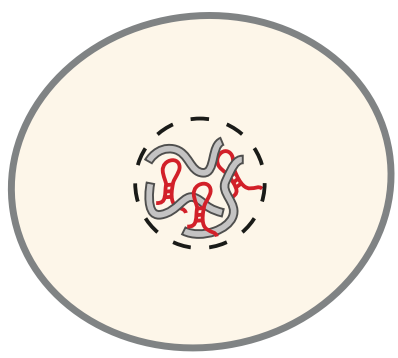

B

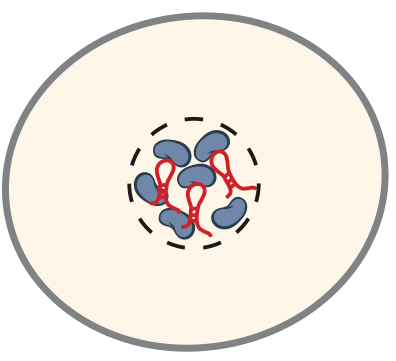

C

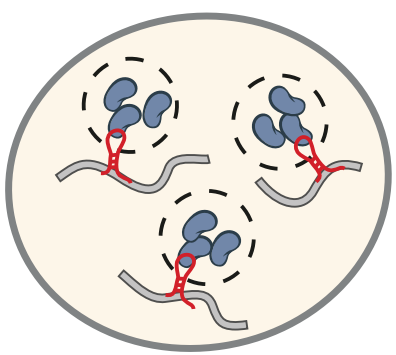

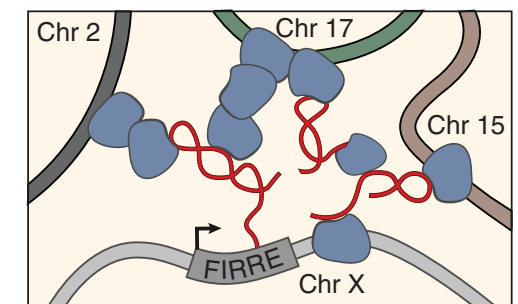
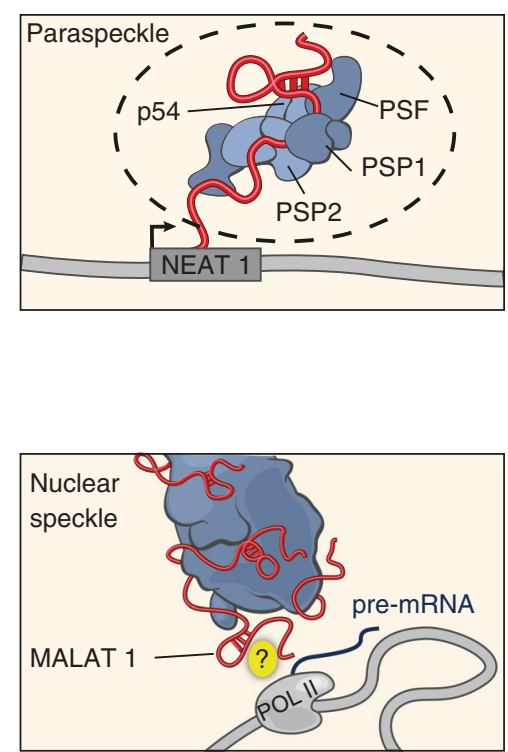

Figure 5. Examples of long noncoding RNAs (lncRNAs) forming dynamic spatial compartments in the nucleus by interacting with DNA, RNA, and protein. (A) Firre interacts with multiple functionally related loci on different chromosomes, brought together into a single nuclear territory for co-regulation. A high local concentration of Firre is required to form this structure. $(B)$ Neat1 expression nucleates paraspeckle formation in the nucleus, creating phaseseparated domains that may also contain additional RNA species. It is unclear if the role of paraspeckles is to coordinate RNA biogenesis and processing, or to trap and sequester molecules away from the rest of the nucleus. (C) Malat1 binds nascent pre-RNAs and splicing factors in nuclear speckles and also interacts with hundreds of actively transcribed DNA loci, potentially integrating transcription and splicing within the same nuclear structure. 
2011), bring together multiple chromosomal loci for common chromatin modifications within nuclear territories (e.g., Polycomb bodies and the inactive X) (Delest et al. 2012), or sequester RNA binding proteins and regulatory RNAs to titrate them away from other regions of the nucleus (e.g., paraspeckles) (Mao et al. 2011; Fox et al. 2018). In addition to nucleating functional domains within the nucleoplasm, lncRNAs can also tether these structures to chromatin through association with DNA-binding proteins such as SAF-A/hnRNPU, and localize them to particular nuclear territories, as is the case with Xist interacting with LBR to associate the $\mathrm{Xi}$ with the nuclear lamina (Chen et al. 2016), coordinating higher levels of organization.

A model of liquid-liquid phase separation in the nucleoplasm has recently been proposed to explain the dynamic formation of membraneless nuclear compartments to coordinately regulate different aspects of gene expression (Hyman et al. 2014; Engreitz et al. 2016b; Hnisz et al. 2017). A central tenant of this model is that cooperative interactions between high local concentrations of nucleic acids and proteins-particularly those with intrinsically disordered domains, present in many RBPs-can lead to the formation of phase-separated bodies that compartmentalize biochemical functions in cells. High local concentrations of lncRNAs recruiting and concentrating proteins into IncRNA-protein structures could nucleate such events, thus dynamically organizing nuclear structures and functions into discrete domains (Fig. 5). In addition, lncRNAs may also act to create phase separated compartments within the nucleoplasm or cytoplasm. Such phase separated structures, however, are large and complex, containing dozens to thousands of distinct chromatin, RNA, and protein components occupying relatively large volumes in cells. Current methods such as microscopy, RNA purification, and $\mathrm{Hi}-\mathrm{C}$ can be combined to study the individual components of nuclear bodies and territories, but are incapable of comprehensively characterizing how molecules simultaneously associate to function within an individual nucleus. A new method recently developed uses split-and-pool barcoding of cross-linked nucleic acids and proteins to define their associations in higher-order structures (Quinodoz et al. 2018). In the future, such methods will allow simultaneous mapping of multiple RNAs and DNA targets that co-occur within 3D structures in the nucleus. In addition, new developments in CRISPRbased live-cell imaging will make it possible to map large numbers of RNA and DNA structural dynamics as they occur in real time (Maass et al. 2018), a critical requirement for studying the role of RNA in phase separation, shaping genome organization, and gene regulation across time.

\section{REFERENCES}

Almeida M, Pintacuda G, Masui O, Koseki Y, Gdula M, Cerase A, Brown D, Mould A, Innocent C, Nakayama M, et al. 2017. PCGF3/5-PRC1 initiates Polycomb recruitment in $\mathrm{X}$ chromosome inactivation. Science 356: $1081-1084$

Brockdorff N, Ashworth A, Kay GF, Cooper P, Smith S, McCabe VM, Norris DP, Penny GD, Patel D, Rastan S. 1991. Conservation of position and exclusive expression of mouse Xist from the inactive X chromosome. Nature 351: 329-331.

Brown CJ, Baldry SE. 1996. Evidence that heteronuclear proteins interact with XIST RNA in vitro. Somat Cell Mol Genet 22: 403-417.

Brown CJ, Ballabio A, Rupert JL, Lafreniere RG, Grompe M, Tonlorenzi R, Willard HF. 1991. A gene from the region of the human X inactivation centre is expressed exclusively from the inactive $\mathrm{X}$ chromosome. Nature 349: 38-44.

Cabili MN, Trapnell C, Goff L, Koziol M, Tazon-Vega B, Regev A, Rinn JL. 2011. Integrative annotation of human large intergenic noncoding RNAs reveals global properties and specific subclasses. Genes Dev 25: 1915-1927.

Cabili MN, Dunagin MC, McClanahan PD, Biaesch A, Padovan-Merhar O, Regev A, Rinn JL, Raj A. 2015. Localization and abundance analysis of human lncRNAs at single-cell and single-molecule resolution. Genome Biol 16: 20.

Cerase A, Smeets D, Tang YA, Gdula M, Kraus F, Spivakov M, Moindrot B, Leleu M, Tattermusch A, Demmerle J, et al. 2014. Spatial separation of Xist RNA and Polycomb proteins revealed by superresolution microscopy. Proc Natl Acad Sci 111: 2235-2240.

Chaumeil J, Le Baccon P, Wutz A, Heard E. 2006. A novel role for Xist RNA in the formation of a repressive nuclear compartment into which genes are recruited when silenced. Genes Dev 20: 2223-2237.

Chen C-KC-K, Blanco M, Jackson C, Aznauryan E, Ollikainen N, Surka C, Chow A, Cerase A, McDonel P, Guttman M. 2016. Xist recruits the $\mathrm{X}$ chromosome to the nuclear lamina to enable chromosome-wide silencing. Science 354: 468-472.

Chu C, Qu K, Zhong FL, Artandi SE, Chang HY. 2011. Genomic maps of long noncoding RNA occupancy reveal principles of RNA-chromatin interactions. Mol Cell 44: 667-678.

Chu C, Zhang QCC, da Rocha ST, Flynn RAA, Bharadwaj M, Calabrese JM, Magnuson T, Heard E, Chang HYY, da Rocha ST, et al. 2015. Systematic discovery of Xist RNA binding proteins. Cell 161: 404-416.

Cirillo D, Blanco M, Armaos A, Buness A, Avner P, Guttman M, Cerase A, Tartaglia GG. 2016. Quantitative predictions of protein interactions with long noncoding RNAs. Nat Methods 14: 5-6.

Clemson CM, McNeil JA, Willard HF, Lawrence JB. 1996. XIST RNA paints the inactive $\mathrm{X}$ chromosome at interphase: Evidence for a novel RNA involved in nuclear/chromosome structure. J Cell Biol 132: 259275.

Clemson CM, Hutchinson JN, Sara SA, Ensminger AW, Fox AH, Chess A, Lawrence JB. 2009. An architectural role for a nuclear noncoding RNA: NEAT1 RNA is essential for the structure of paraspeckles. Mol Cell 33: 717-726.

da Rocha ST, Heard E. 2017. Novel players in X inactivation: Insights into Xist-mediated gene silencing and chromosome conformation. Nat Struct Mol Biol 24: 197-204.

da Rocha ST, Boeva V, Escamilla-Del-Arenal M, Ancelin K, Granier C, Matias NR, Sanulli S, Chow J, Schulz E, Picard C, et al. 2014. Jarid2 is implicated in the initial Xist-induced targeting of PRC2 to the inactive X chromosome. Mol Cell 53: 301-316.

Darnell RB. 2010. HITS-CLIP: Panoramic views of protein-RNA regulation in living cells. Wiley Interdiscip Rev RNA 1: 266-286.

Davidovich C, Zheng L, Goodrich KJ, Cech TR. 2013. Promiscuous RNA binding by Polycomb repressive complex 2. Nat Struct Mol Biol 20: $1250-1257$.

Delest A, Sexton T, Cavalli G. 2012. Polycomb: A paradigm for genome organization from one to three dimensions. Curr Opin Cell Biol 24: 405-414. 
Derrien T, Johnson R, Bussotti G, Tanzer A, Djebali S, Tilgner H, Guernec G, Martin D, Merkel A, Knowles DG, et al. 2012. The GENCODE v7 catalog of human long noncoding RNAs: Analysis of their gene structure, evolution, and expression. Genome Res 22: 1775-1789.

Duthie SM, Nesterova TB, Formstone EJ, Keohane AM, Turner BM, Zakian SM, Brockdorff N. 1999. Xist RNA exhibits a banded localization on the inactive $\mathrm{X}$ chromosome and is excluded from autosomal material in cis. Hum Mol Genet 8: 195-204.

Engreitz JMM, Pandya-Jones A, McDonel P, Shishkin A, Sirokman K, Surka C, Kadri S, Xing J, Goren A, Lander ESS, et al. 2013. The Xist lncRNA exploits three-dimensional genome architecture to spread across the X chromosome. Science 341: 1237973.

Engreitz JM, Sirokman K, McDonel P, Shishkin AA, Surka C, Russell P, Grossman SR, Chow AY, Guttman M, Lander ES. 2014. RNA-RNA interactions enable specific targeting of noncoding RNAs to nascent pre-mRNAs and chromatin sites. Cell 159: 188-199.

Engreitz JM, Haines JE, Perez EM, Munson G, Chen J, Kane M, McDonel PE, Guttman M, Lander ES. 2016a. Local regulation of gene expression by lncRNA promoters, transcription and splicing. Nature 539: $452-$ 455.

Engreitz JM, Ollikainen N, Guttman M. 2016b. Long non-coding RNAs: Spatial amplifiers that control nuclear structure and gene expression. Nat Rev Mol Cell Biol 17: 756-770.

Fox AH, Nakagawa S, Hirose T, Bond CS. 2018. Paraspeckles: Where long noncoding RNA meets phase separation. Trends Biochem Sci 43: $124-135$.

Fulco CP, Munschauer M, Anyoha R, Munson G, Grossman SR, Perez EM, Kane M, Cleary B, Lander ES, Engreitz JM. 2016. Systematic mapping of functional enhancer-promoter connections with CRISPR interference. Science 354: 769-773.

Ghildiyal M, Zamore PD. 2009. Small silencing RNAs: An expanding universe. Nat Rev Genet 10: 94-108.

Groff AF, Sanchez-Gomez DB, Soruco MML, Gerhardinger C, Barutcu AR, Li E, Elcavage L, Plana O, Sanchez LV, Lee JC, et al. 2016. In vivo characterization of Linc-p21 reveals functional cis-regulatory DNA elements. Cell Rep 16: 2178-2186.

Guttman M, Amit I, Garber M, French C, Lin MF, Feldser D, Huarte M, Zuk O, Carey BW, Cassady JP, et al. 2009. Chromatin signature reveals over a thousand highly conserved large non-coding RNAs in mammals. Nature 458: 223-227.

Guttman M, Donaghey J, Carey BW, Garber M, Grenier JKK, Munson G, Young G, Lucas AB, Ach R, Bruhn L, et al. 2011. lincRNAs act in the circuitry controlling pluripotency and differentiation. Nature 477: 295-300.

Guttman M, Russell P, Ingolia NT, Weissman JS, Lander ES. 2013. Ribosome profiling provides evidence that large noncoding RNAs do not encode proteins. Cell 154: 240-251.

Hacisuleyman E, Goff LA, Trapnell C, Williams A, Henao-Mejia J, Sun L, McClanahan P, Hendrickson DG, Sauvageau M, Kelley DR, et al. 2014. Topological organization of multichromosomal regions by the long intergenic noncoding RNA Firre. Nat Struct Mol Biol 21: 198206.

Hasegawa Y, Brockdorff N, Kawano S, Tsutui K, Tsutui K, Nakagawa S. 2010. The matrix protein hnRNP $\mathrm{U}$ is required for chromosomal localization of Xist RNA. Dev Cell 19: 469-476.

Herzing LB, Romer JT, Horn JM, Ashworth A. 1997. Xist has properties of the X-chromosome inactivation centre. Nature 386: 272-275.

Hnisz D, Shrinivas K, Young RA, Chakraborty AK, Sharp PA. 2017. A phase separation model for transcriptional control. Cell 169: $13-23$.

Huarte M, Guttman M, Feldser D, Garber M, Koziol MJ, KenzelmannBroz D, Khalil AM, Zuk O, Amit I, Rabani M, et al. 2010. A large intergenic noncoding RNA induced by p53 mediates global gene repression in the $\mathrm{p} 53$ response. Cell 142: 409-419.

Hyman A, Weber CA, Jülicher F. 2014. Liquid-liquid phase separation in biology. Annu Rev Cell Dev Biol 30: 39-58.
Kalantry S, Magnuson T. 2006. The Polycomb group protein EED is dispensable for the initiation of random X-chromosome inactivation. PLoS Genet 2: e66.

Keryer-Bibens C, Barreau C, Beverley Osborne H, Osborne HB. 2008. Tethering of proteins to RNAs by bacteriophage proteins. Biol Cell 100: 125-138.

Khalil AM, Guttman M, Huarte M, Garber M, Raj A, Rivea Morales D, Thomas K, Presser A, Bernstein BE, Van Oudenaarden A, et al. 2009. Many human large intergenic noncoding RNAs associate with chromatin-modifying complexes and affect gene expression. Proc Natl Acad Sci 106: 11667-11672.

Kohlmaier A, Savarese F, Lachner M, Martens J, Jenuwein T, Wutz A. 2004. A chromosomal memory triggered by Xist regulates histone methylation in X inactivation. PLoS Biol 2: E171.

Konig J, Zarnack K, Rot G, Curk T, Kayikci M, Zupan B, Turner DJ, Luscombe NM, Ule J. 2010. iCLIP reveals the function of hnRNP particles in splicing at individual nucleotide resolution. Nat Struct Mol Biol 17: 909-915.

Kopp F, Mendell JT. 2018. Functional classification and experimental dissection of long noncoding RNAs. Cell 172: 393-407.

Lee JT, Strauss WM, Dausman JA, Jaenisch R. 1996. A $450 \mathrm{~kb}$ transgene displays properties of the mammalian $\mathrm{X}$-inactivation center. Cell 86: 83-94.

Lee HY, Haurwitz RE, Apffel A, Zhou K, Smart B, Wenger CD, Laderman S, Bruhn L, Doudna JA. 2013. RNA-protein analysis using a conditional CRISPR nuclease. Proc Natl Acad Sci 110: 5416-5421.

Lee S, Kopp F, Chang T-C, Sataluri A, Chen B, Sivakumar S, Yu H, Xie Y, Mendell JT. 2016. Noncoding RNA NORAD regulates genomic stability by sequestering PUMILIO proteins. Cell 164: 69-80.

Liang X-H, Sun H, Nichols JG, Crooke ST. 2017. RNase H1-dependent antisense oligonucleotides are robustly active in directing RNA cleavage in both the cytoplasm and the nucleus. Mol Ther 25: 2075-2092.

Liu SJ, Liu SJ, Horlbeck MA, Cho SW, Birk HS, Malatesta M, Attenello FJ, Villalta JE, Cho MY, Chen Y, et al. 2016. CRISPRi-based genome-scale identification of functional long noncoding RNA loci in human cells. Science 355: aah7111.

Maass PG, Barutcu AR, Shechner DM, Weiner CL, Melé M, Rinn JL. 2018. Spatiotemporal allele organization by allele-specific CRISPR live-cell imaging (SNP-CLING). Nat Struct Mol Biol 25: 176-184.

Mao YS, Sunwoo H, Zhang B, Spector DL. 2011. Direct visualization of the co-transcriptional assembly of a nuclear body by noncoding RNAs. Nat Cell Biol 13: 95-101.

McHugh CA, Russell P, Guttman M. 2014. Methods for comprehensive experimental identification of RNA-protein interactions. Genome Biol 15: 203.

McHugh CA, Chen C-K, Chow A, Surka CF, Tran C, McDonel P, PandyaJones A, Blanco M, Burghard C, Moradian A, et al. 2015. The Xist IncRNA interacts directly with SHARP to silence transcription through HDAC3. Nature 521: 232-236.

Mili S, Steitz JA. 2004. Evidence for reassociation of RNA-binding proteins after cell lysis: Implications for the interpretation of immunoprecipitation analyses. RNA 10: 1692-1694.

Minajigi A, Froberg JE, Wei C, Sunwoo H, Kesner B, Colognori D, Lessing D, Payer B, Boukhali M, Haas W, et al. 2015. Chromosomes. A comprehensive Xist interactome reveals cohesin repulsion and an RNAdirected chromosome conformation. Science 349: aab2276.

Moindrot B, Cerase A, Coker H, Masui O, Grijzenhout A, Pintacuda G, Schermelleh L, Nesterova TB, Brockdorff N. 2015. A pooled shRNA screen identifies Rbm15, Spen, and Wtap as factors required for Xist RNA-mediated silencing. Cell Rep 12: 562-572.

Monfort A, Minin G Di, Postlmayr A, Arieti F, Wutz A. 2015. Identification of Spen as a crucial factor for Xist function through forward genetic screening in haploid embryonic stem cells. Cell Rep 12: 554561.

Nagano T, Mitchell JA, Sanz LA, Pauler FM, Ferguson-Smith AC, Feil R, Fraser P. 2008. The Air noncoding RNA epigenetically silences transcription by targeting G9a to chromatin. Science 322: 1717-1720. 
Ozdilek BA, Thompson VF, Ahmed NS, White CI, Batey RT, Schwartz JC. 2017. Intrinsically disordered RGG/RG domains mediate degenerate specificity in RNA binding. Nucleic Acids Res 45: 7984-7996.

Patil DP, Chen CK, Pickering BF, Chow A, Jackson C, Guttman M, Jaffrey SR. 2016. M6A RNA methylation promotes XIST-mediated transcriptional repression. Nature 537: 369-373.

Penny GD, Kay GF, Sheardown SA, Rastan S, Brockdorff N. 1996. Requirement for Xist in X chromosome inactivation. Nature 379: 131-137.

Pintacuda G, Wei G, Roustan C, Kirmizitas BA, Solcan N, Cerase A, Castello A, Mohammed S, Moindrot B, Nesterova TB, et al. 2017. hnRNPK recruits PCGF3/5-PRC1 to the Xist RNA B-repeat to establish Polycomb-mediated chromosomal silencing. Mol Cell 68: 955-969.e10.

Plath K, Fang J, Mlynarczyk-Evans SK, Cao R, Worringer KA, Wang H, de la Cruz CC, Otte AP, Panning B, Zhang Y. 2003. Role of histone H3 lysine 27 methylation in X inactivation. Science 300: 131-135.

Portoso M, Ragazzini R, Brenčič Ž, Moiani A, Michaud A, Vassilev I, Wassef M, Servant N, Sargueil B, Margueron R. 2017. PRC2 is dispensable for HOTAIR-mediated transcriptional repression. EMBO J 36: 981-994.

Quinodoz SA, Ollikainen N, Tabak B, Palla A, Schmidt JM, Detmar E, Lai MM, Shishkin AA, Bhat P, Takei Y, et al. 2018. Higher-order interchromosomal Hubs shape 3D genome organization in the nucleus. Cell 174: 744-757.e24.

Rinn JL, Chang HY. 2012. Genome regulation by long noncoding RNAs. Annu Rev Biochem 81: 145-166.

Rogell B, Fischer B, Rettel M, Krijgsveld J, Castello A, Hentze MW. 2017. Specific RNP capture with antisense LNA/DNA mixmers. RNA 23: 1290-1302.

Sauvageau M, Goff LA, Lodato S, Bonev B, Groff AF, Gerhardinger C, Sanchez-Gomez DB, Hacisuleyman E, Li E, Spence M, et al. 2013. Multiple knockout mouse models reveal lincRNAs are required for life and brain development. Elife 2: e01749.

Schoeftner S, Sengupta AK, Kubicek S, Mechtler K, Spahn L, Koseki H, Jenuwein T, Wutz A. 2006. Recruitment of PRC1 function at the initiation of $\mathrm{X}$ inactivation independent of PRC2 and silencing. EMBO J 25: $3110-3122$

Shechner DM, Hacisuleyman E, Younger ST, Rinn JL. 2015. Multiplexable, locus-specific targeting of long RNAs with CRISPR-Display. Nat Methods 12: 664-670.

Shevtsov SP, Dundr M. 2011. Nucleation of nuclear bodies by RNA. Nat Cell Biol 13: 167-173.
Simon MD, Pinter SF, Fang R, Sarma K, Rutenberg-Schoenberg M, Bowman SK, Kesner BA, Maier VK, Kingston RE, Lee JT. 2013. High-resolution Xist binding maps reveal two-step spreading during X-chromosome inactivation. Nature 504: 465-469.

Soruco MML, Chery J, Bishop EP, Siggers T, Tolstorukov MY, Leydon AR, Sugden AU, Goebel K, Feng J, Xia P, et al. 2013. The CLAMP protein links the MSL complex to the X chromosome during Drosophila dosage compensation. Genes Dev 27: 1551-1556.

Spector DL, Lamond AI. 2011. Nuclear speckles. Cold Spring Harb Perspect Biol 3: a000646.

Srisawat C, Engelke DR. 2002. RNA affinity tags for purification of RNAs and ribonucleoprotein complexes. Methods 26: 156-161.

Terranova R, Yokobayashi S, Stadler MB, Otte AP, van Lohuizen M, Orkin SH, Peters AHFM. 2008. Polycomb group proteins Ezh2 and Rnf2 direct genomic contraction and imprinted repression in early mouse embryos. Dev Cell 15: 668-679.

Tripathi V, Ellis JD, Shen Z, Song DY, Pan Q, Watt AT, Freier SM, Bennett CF, Sharma A, Bubulya PA, et al. 2010. The nuclear-retained noncoding RNA MALAT1 regulates alternative splicing by modulating SR splicing factor phosphorylation. Mol Cell 39: 925-938.

Wang KC, Yang YW, Liu B, Sanyal A, Corces-Zimmerman R, Chen Y, Lajoie BR, Protacio A, Flynn RA, Gupta RA, et al. 2011. A long noncoding RNA maintains active chromatin to coordinate homeotic gene expression. Nature 472: 120-124.

Wapinski O, Chang HY. 2011. Long noncoding RNAs and human disease. Trends Cell Biol 21: 354-361.

Werner MS, Ruthenburg AJ. 2015. Nuclear fractionation reveals thousands of chromatin-tethered noncoding RNAs adjacent to active genes. Cell Rep 12: 1089-1098.

West JA, Davis CP, Sunwoo H, Simon MD, Sadreyev RI, Wang PI, Tolstorukov MY, Kingston RE. 2014. The long noncoding RNAs NEAT1 and MALAT1 bind active chromatin sites. Mol Cell 55: 791802.

Wutz A, Rasmussen TP, Jaenisch R. 2002. Chromosomal silencing and localization are mediated by different domains of Xist RNA. Nat Genet 30: $167-174$.

Zhao J, Sun BK, Erwin JA, Song JJ, Lee JT. 2008. Polycomb proteins targeted by a short repeat RNA to the mouse X chromosome. Science 322: 750-756.

Zhao J, Ohsumi TK, Kung JT, Ogawa Y, Grau DJ, Sarma K, Song JJ, Kingston RE, Borowsky M, Lee JT. 2010. Genome-wide identification of Polycomb-associated RNAs by RIP-seq. Mol Cell 40: 939-953. 


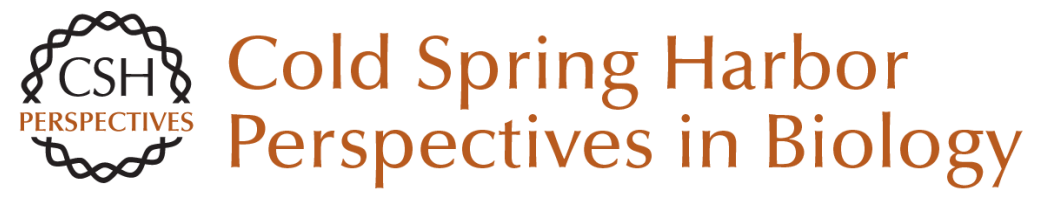

\title{
Approaches for Understanding the Mechanisms of Long Noncoding RNA Regulation of Gene Expression
}

\author{
Patrick McDonel and Mitchell Guttman \\ Cold Spring Harb Perspect Biol 2019; doi: 10.1101/cshperspect.a032151
}

\section{Subject Collection RNA Worlds}

Alternate RNA Structures

Marie Teng-Pei Wu and Victoria D'Souza

Approaches for Understanding the Mechanisms of Long Noncoding RNA Regulation of Gene Expression

Patrick McDonel and Mitchell Guttman

Principles and Practices of Hybridization Capture Experiments to Study Long Noncoding RNAs That Act on Chromatin Matthew D. Simon and Martin Machyna

Linking RNA Sequence, Structure, and Function on Massively Parallel High-Throughput Sequencers Sarah K. Denny and William J. Greenleaf

Extensions, Extra Factors, and Extreme Complexity: Ribosomal Structures Provide Insights into Eukaryotic Translation Melanie Weisser and Nenad Ban

Nascent RNA and the Coordination of Splicing with Transcription

Karla M. Neugebauer

Combining Mass Spectrometry (MS) and Nuclear Magnetic Resonance (NMR) Spectroscopy for Integrative Structural Biology of Protein-RNA Complexes

Alexander Leitner, Georg Dorn and Frédéric H.-T. Allain

For additional articles in this collection, see http://cshperspectives.cshlp.org/cgi/collection/

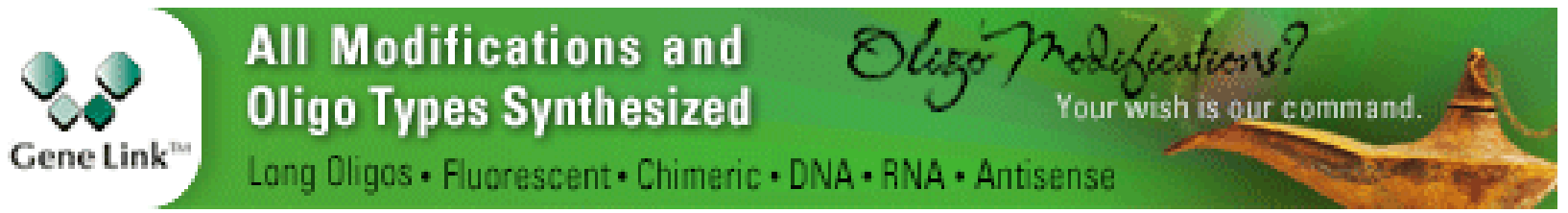

Structural Biology of Telomerase

Yaqiang Wang, Lukas Susac and Juli Feigon

Structural Insights into Nuclear pre-mRNA

Splicing in Higher Eukaryotes

Berthold Kastner, Cindy L. Will, Holger Stark, et al.

What Are 3' UTRs Doing?

Christine Mayr

Single-Molecule Analysis of Reverse

Transcriptase Enzymes

Linnea I. Jansson and Michael D. Stone

CRISPR Tools for Systematic Studies of RNA

Regulation

Jesse Engreitz, Omar Abudayyeh, Jonathan

Gootenberg, et al.

Relating Structure and Dynamics in RNA Biology Kevin P. Larsen, Junhong Choi, Arjun Prabhakar, et al.

Beyond DNA and RNA: The Expanding Toolbox of Synthetic Genetics

Alexander I. Taylor, Gillian Houlihan and Philipp Holliger

Copyright @ 2019 Cold Spring Harbor Laboratory Press; all rights reserved 
Discovering and Mapping the Modified Nucleotides That Comprise the Epitranscriptome of mRNA

Bastian Linder and Samie R. Jaffrey
Structural Basis of Nuclear pre-mRNA Splicing:

\section{Lessons from Yeast}

Clemens Plaschka, Andrew J. Newman and Kiyoshi Nagai

For additional articles in this collection, see http://cshperspectives.cshlp.org/cgi/collection/

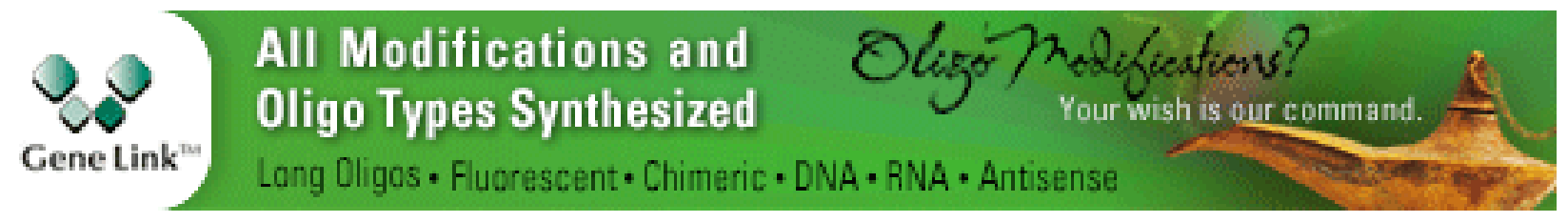

Copyright (C) 2019 Cold Spring Harbor Laboratory Press; all rights reserved 